\title{
Jse of a Bird House By a Wasp Colony
}

By ROBERT W. NERO, Saskatchewan Museum of Natural History

In the fall of 1953, Mr. Irving arce, of Tonkin, Saskatchewan, ought to the museum a bird house hich had been used as a nest-site a colony of paper-wasps (see otos). The complete utilization hich is evident in this case rnay be ique and is worth recording. Dr. Bequaert, entomologist and wasp ecialist, formerly with the Harvard useum of Comparative Zoology, mmented on this nest as follows: $t$ illustrates once more how adaptle the nesting instincts of social asps can be, in selecting and coping th an unforeseen environment. I n not aware that a similar case has en recorded before in print, alough other types of abnormal nests social wasps have been described om time to time." (pers. corres.)

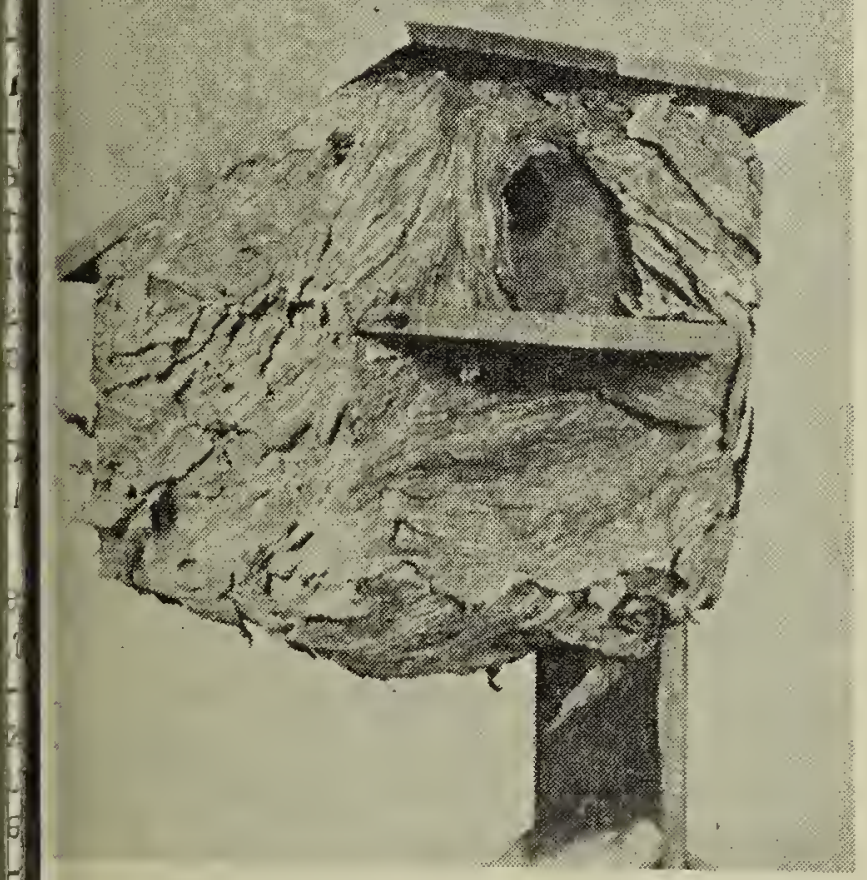

Sask. Govt. Photo en house converted into living quarters by paper-making wasps.

Mr. Pearce writes that he had put several similar bird-houses to tract wrens. This one had been aced in a maple tree about ten et from the ground and only a w yards from his home. Wrens ere not observed to nest in the box it late in the summer of 1953 it as noticed that wasps had built inle it. "We never molested them and it wasn't very long before they started to cover the outside. When they had left in the fall we took it down."

Note the extent to which the outside of the unpainted box has been covered with paper (the front edge of the roof measures 7 inches). Ordinarily, of course, these wasps build a nest which is globular. In this instance their instinctive patterns of building have been modified to work on the basis of a cubical structure. The bird house has been almost completely covered with paper on four sides. The bottom is only partly covered around the edges. A seam in the roof has been very nicely sealed by a single layer of paper. In other places the paper is several layers thick. (Seven layers on the back of

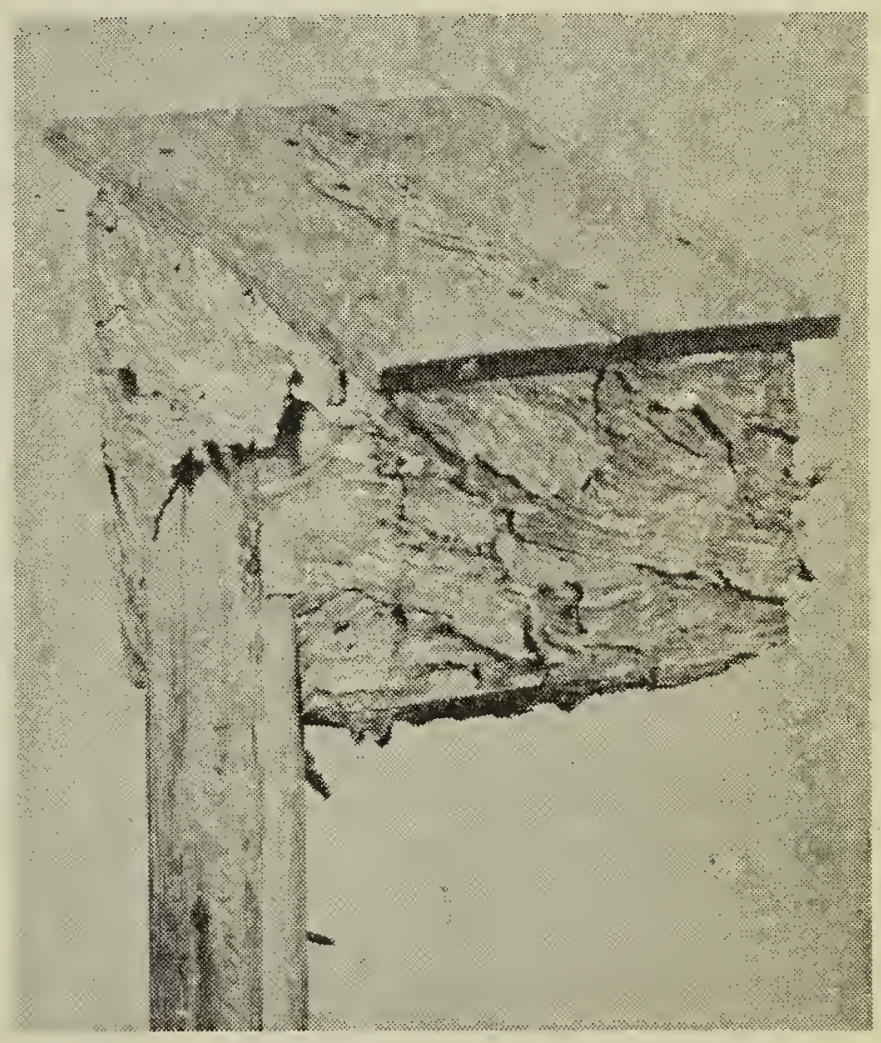

Sask. Govt. Photo Roof of wren house showing crack sealed with paper.

the box.). The entrance, which is seven-eights of an inch in diameter, has been surrounded by paper which extends right to the upper left edge of the hole but which is otherwise well back from the hole. Since the wasps build their paper structure in degrees, utilizing bits of more or less decayed wood from different sources, a tree-ring-like pattern of increment 
is apparent. Paper was added around the entrance hole in a circular manner. The use of this hole indicates another modification of the usual pattern of the nest-site. Ordinarily, the entrance is at the base of the nest. Most of the paper is of the typical gray color but there are a few segments which are rather brightly colored. A bluish-green strand is apparent in two places, and a reddish-brown strand appears in three different places. We might, ask $\mathrm{Mr}$. Pearce to hazard a guess as to the source of this colored wood!

The interior of the bird-house was completely utilized for the combstructure. Ordinarily, wasps begin with a small nest which consists of a single horizontal comb enclosed in a paper envelope. Enlargement of the nest entails tearing down the inner walls of the envelope. Presumably, this took place within the bird house until the limits of its walls were reached, at which point paper was added to the outside of the house. This colony was thus foredoomed to a limited size by its selection of this nest-site.
Dead wasps, found in the interio of the bird-house after carefully re moving one section of the roof, wer forwarded in April, 1957, to Mr. C. D F. Miller, Dept. Agric., Ottawa, wh kindly identified them as Vespul (Dolichovespula) arenaria (Fabr. Acocrding to Mr. Miler, this specie is widely distributed througout Nort] America in the boreal region and ca be considered as our most commo wasp. These wasps typically build large nest attached to the branch a bush or tree.

Wasps of ancther species (Vespul squamosa (Dru) built a nest in th end of a rolled-up rug suspended i a garage in Florida in Decembes 1952 , according to A. N. Tissot an F. A. Robinson (1954. Some unusue insect nests. The Florida Entomalo gist, 37: 73-92). This observation an others received considerable atter tion because this species had bee formerly supposed to nest under ground. Once again, simple observo tions refute published "facts" an point to the need for further stud of our most common insects.

\section{Collecting Moths and Butterflies as a Hobb}

Notes from lectures given by A. O. ASCHIM, Prince Albert, to the Prin Albert Natural History Society

A most rewarding study of nature can be made through collecting moths and butterflies, either as a scientific pursuit or as a simple hobby with a large number of possibilities. This hobby is open to the young and the old, the rich and the poor, the expert and the novice. It is so flexible that it can be a mere pastime, or as serious a study as one wishes to make it. It can be related to other studies of nature, and the moths and butterflies themselves are so numerous and varied, that this hobby is practically unlimited in scope.

The height of a collector's ambition would probably be a scientific collection, correctly classified, neatly mounted and stored. However, this hobby has other interesting facets. Showy specimens mounted under glass make beautiful mounts for home display and for gifts or exchanges. They are also acceptable in serving trays, ashtrays, bronches, ear-rings, etc. The wings of mot? and butterflies may be used to ma artistic designs. You can collect spec mens for photographic purposes as make beautiful transparencies with $35 \mathrm{~mm}$. camera.

\section{COLLECTING APPARATUS}

Collecting nets may be purchas or made at home. It is useful to ha two or three sizes, including a lar net with a fourteen inch hoop and bag about thirty inches long. $T$ handle should be of light, stro wood, not heavier than a broom ha dle. The net itself should be funn shaped but sewn across the bottc about four inches frcm the apex that the ingect can be retrieved wit out injury. One should also have twelve inch net, and for some pi poses an eight inch net. The lens of the bags will be slightly over tw the width of the hoop.

Leno is suitable for the net, $p$ vided a cotton border is sewn arou 